\title{
Enterprise Architecture Planning in developing A planning Information System: a Case Study of Semarang State University
}

\author{
Kholiq Budiman ${ }^{1, *}$, Toni Prahasto ${ }^{2}$, and Amie Kusumawardhani ${ }^{3}$ \\ ${ }^{1}$ Magister Program of Information System, School of Postgraduate Studies, Diponegoro University, Semarang - Indonesia \\ ${ }^{2}$ Department of Mechanical Engineering, Faculty of Engineering, Diponegoro University, Semarang - Indonesia \\ ${ }^{3}$ Department of Accounting, Faculty of Economic and Business, Diponegoro University, Semarang - Indonesia
}

\begin{abstract}
This research has applied an integrated design and development of planning information system, which is been designed using Enterprise Architecture Planning. Frequent discrepancy between planning and realization of the budget that has been made, resulted in ineffective planning, is one of the reason for doing this research. The design using EAP aims to keep development aligned and in line with the strategic direction of the organization. In the practice, EAP is carried out in several stages of the planning initiation, identification and definition of business functions, proceeded with architectural design and EA implementation plan that has been built. In addition to the design of the Enterprise Architecture, this research carried out the implementation, and was tested by several methods of black box and white box. Black box testing method is used to test the fundamental aspects of the software, tested by two kinds of testing, first is using User Acceptance Testing and the second is using software functionality testing. White box testing method is used to test the effectiveness of the code in the software, tested using unit testing. Tests conducted using white box and black box on the integrated planning information system, is declared successful. Success in the software testing can not be ascertained if the software built has not shown any distinction from prior circumstance to the development of this integrated planning information system. For ensuring the success of this system implementation, the authors test consistency between the planning of data and the realization of prior-use of the information system, until after-use information system. This consistency test is done by reducing the time data of the planning and realization time. From the tabulated data, the planning information system that has been built reduces the difference between the planning time and the realization time, in which indicates that the planning information system can motivate the planner unit in realizing the budget that has been designed. It also proves that the value chain of the information planning system has brought implications for budget realization.
\end{abstract}

\section{Introduction}

Weak and not mature planning in a government budget process resulting in low absorption of the budget. The minimum absorption can be prevented by revising the budget during the unaccomplished budget period. However, because the delivery of a limited budget revisions make the realization of the budget in the unit not the same as planning revision resulted in the reporting process will be more difficult to do. If the revised budget reporting process is not easy, then it will take a long time to report budget changes, causing the budget too long to be arranged, it shows the weakness of budgeting [1]. With the help of information systems, budget report will be easier, because administrative data that is processed will be more accurate and human errors will be more easily prevented too.

The construction and development of information systems should be in harmony and in accordance with the organization's (Enterprise) strategic direction, many cases of failure of information systems management in achieving the objectives organization, because the way using and building the information system not in accordance with the direction and goals and needs [2]. Enterprise architecture is very important for the conversion of information systems and develop a new system that will optimize the company's mission. This is achieved in terms of logical or business (eg, objectives and business functions, information flow, and the environment outside the system) and technical (e.g., software, hardware, communications), and includes plans harmonization for the transition from basic environment to targeted e-government environment [3]. To the real needs that exist in the budget absorption effective enterprise architecture also did not excluded rules that are used as budgetary constraints.

\section{Theory}

\subsection{Enterprise Architecture}

Architecture is an area of science in information systems that basically meant to build the foundation of the 
structure, characteristics behaviors and principles as well as a guide, alteration and operation in the making and developing of the system in the long term [4].

Enterprise Architecture(EA) is a representation of the structure and behavior of a company's business processes. This is describe a system that currently exists and the system in the future. EA include:

- An insight into the utilization current information technology in business operations

- A vision for the future utilization of information technology in business operations, and

- A roadmap for the evolution of information technology landscape from the current state to the future state, along with the transient states in between [4].

\subsection{Enterprise Architecture Planning}

Enterprise Architecture Planning (Enterprise Architecture Planning, EAP) is a collection of architectural and strategic fields which include information, business systems, and architectural engineering [5]. EAP is a modern approach to the planning of the quality of data in order to achieve the mission of Information Systems. EAP is also a process of defining a number of architectures, that is: data architecture, application architecture, and architecture in using information technology to support the business. EAP has associated with how to align business strategy with IT strategy in which the organization's business strategy development will be the starting point for determining the IT strategy further. EAP will provide a map of the enterprise and enterprise plan to change the path of business and technology. The linkage between the existing architecture is essential for EAP [5]. It is therefore not developed in isolation enterprise, EAP should be looked at in the perspective of enterprise-wide. The steps in using Enterprise Architecture planning is shown in Fig. 1.

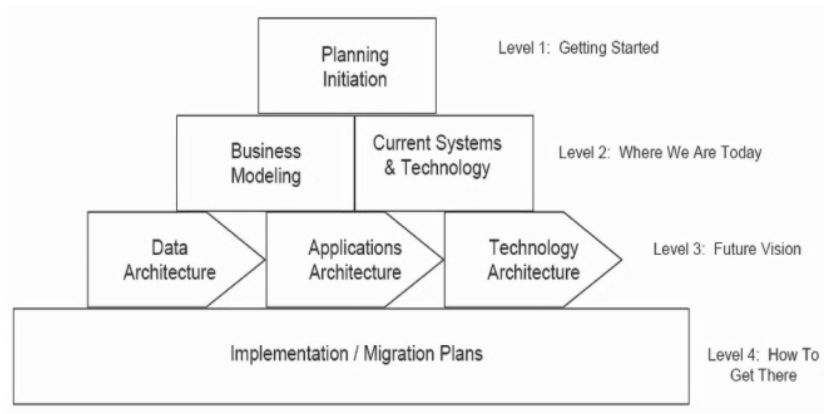

Fig. 1. Layers in the EAP [5]

\subsection{Zachman Framework}

Enterprise Architecture Framework is a set of assumptions, concepts, values and practices that constitute a realistic perspective of a company through the perspective of architectural models. So EA offers fixed structures and assist the designer in developing, maintaining and using EA [4]. Zachman Framework was originally an enterprise modeling tool. Basically Zachman is a 6x6 matrix that defines 6 levels that are relevant for any company. The arrangement provided by the Zachman framework placed on all relevant scales, as well as on all relevant aspects and also take into account all the conditions [6].

\section{ENTERPRISE ARCHITECTURE - A FRAMEWORK ${ }^{\text {TM }}$}

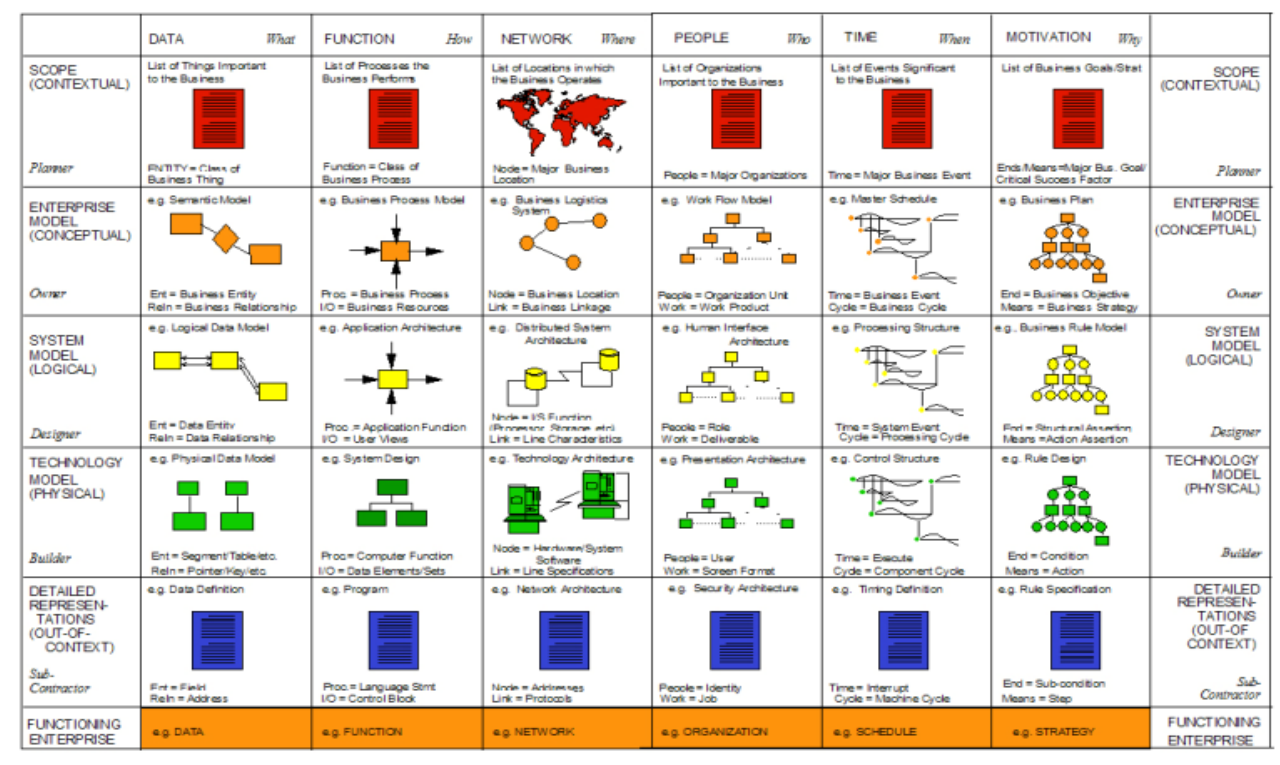

(C)John A. Zachman, Zachman International (810) 231-0531

Reprinted by permission - www.zifa.com

Fig. 2. Zachman Framework [7] 


\subsection{EAP \& Zachman Framework}

EAP is part of the Zachman Framework. in the Zachman Framework, EAP include first and second row of the first three columns as shown in Fig. 3.

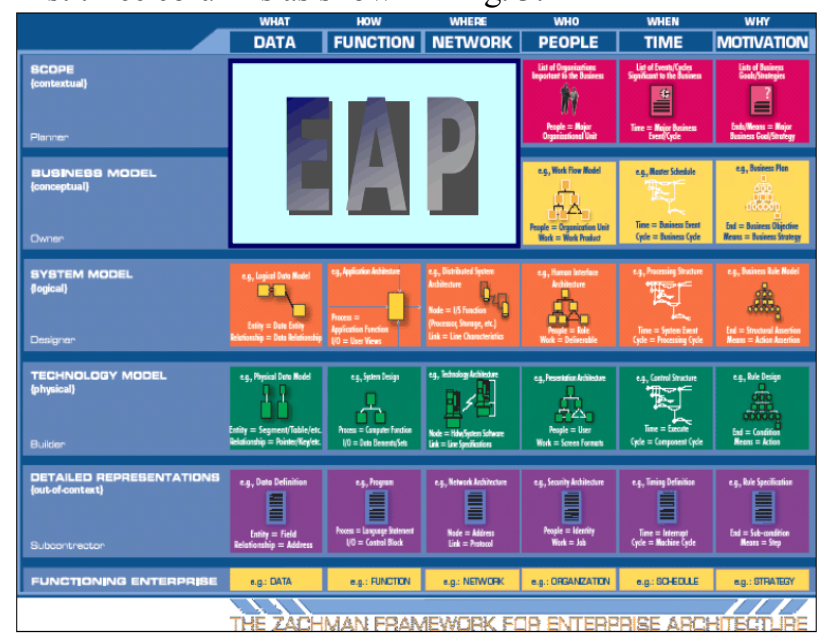

Fig. 3. Relations EAP \& Zachman Framework

\subsection{Value Chain Model (Value Chain)}

Model of value chain consists of a series of activities that create and build a margin value that can generate added value for the organization [8]. The value chain provides a framework for identifying and inventorying areas of business functions is by grouping functional areas into core activities and supporting activities.

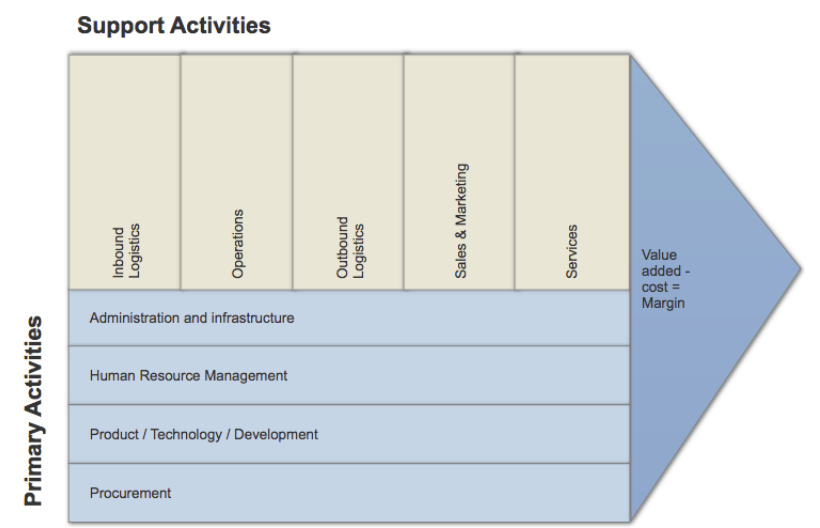

Fig. 4. The Value Chain Model [8]

\subsection{Software Testing}

Software testing used to identify errors of its information system, deficiencies or errors in the application code is must be corrected, this test has the main purpose is to fix errors to guarantee the quality, reliability estimation, validation and verification of software that is built [9]. There are three techniques to look for errors in the software it is White-box test, Black-box test and the Gray-box test [9]. Structural test (or so-called white-box tests and glass-box tests) found a bug in structural elements such low levels structure that occur at the level of code, database schemas, chips, subassemblies and interfaces [10]. Structural testing is based on how a system operates. Black box testing is test intended to test the functionality of the software. This black-box testing ignoring the effectiveness of the internal structure and software. Thus it is programmer or testers get a series of input conditions that fully utilizes all of the functional requirements for a program. While Gray box testing allows testers to focus on all layers of the software by combining Black Box and White Box [9]. By combining the two tests is expected to make the software more effective in its use because the code is structured and has been functioning effectively.

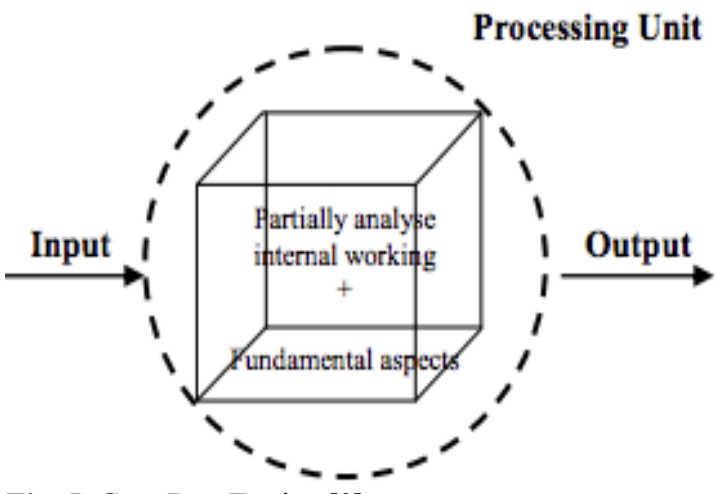

Fig. 5. Gray Box Testing [9]

\subsection{Planning and Budget}

Planning means to predefine possible activities and how to do it. Planning is an effort to anticipate before doing something so that what is done can be managed properly aim is to provide the process feed forward in order to give direction to every manager in decision making daily operations [11], the linkage between planning and budgeting described in the Fig. 6.

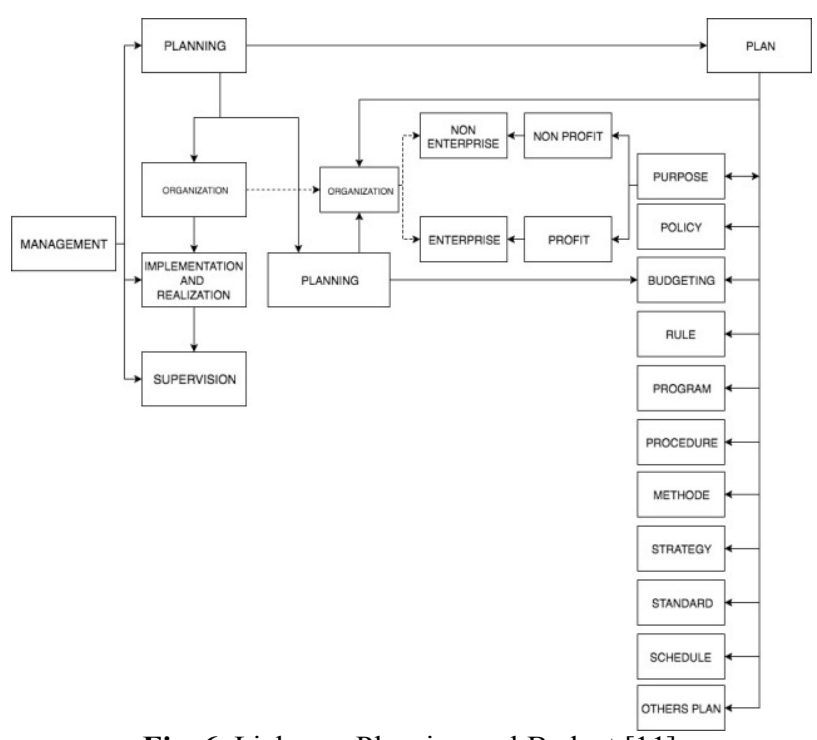

Fig. 6. Linkages Planning and Budget [11]

Budget is a plan of systematically arranged, which covers all activities of the company, which is expressed in units (entity) monetary and valid for a period of time (period) certain to come [12].

In the execution of the budget can be considered effective if it meets several criteria, including: 
- Prediction activities

- Clear rules

- Accounting calculations are accurate, reliable and precise

- Appropriate information and can be easily understood

- Support at all levels of the organization both the most top level to the lowest level in the organization [1].

\section{Research Methods}

\subsection{Initialize method Planning}

The initiation phase is the initial phase of the study in which the author identifies the basic rules that exist within an existing budget budgeting especially those in the case study that is at the University.

\subsection{Methods Identify and define business functions}

At this stage, identification of key functions in budgeting. Based on observations made there are six major functions of budgeting in the University:

- Determining the purpose to determine the plans and strategies of each unit in the university.

- Analyzing the available resources, those in terms of revenue coming from routine income that is from students payment and non-routine income.

- Negotiating in the forecast budget components

- Coordinate and review the budgeting component

- Final approval from policy makers

- Distributing the budget approved

\subsection{Architectural Design Method}

\subsubsection{Data Architecture}

In designing data architecture steps that must be done include :

- Identifying candidates that are possible to support the business entity;

- Identifying modeling data such as hierarchical, network and relational model;

- Make a diagram of relationships between entities. Modeling that describes the relationship between entities can use the E-RD (Entity-Relationalship Diagram)

- Data entities relate to the identification of business functions that have been performed to determine create, read / reference and update the data so that it can be a reference to the development of applications, where entities that support the functions done first because it create a source of data / master data.

\subsubsection{Application Architecture}

In designing application architecture steps that must be done include :
- Identify candidate applications to be created and developed to match the needs of business functions are identified;

- Identify actors and designing use case useful for related actors to business functions that support applications that are built;

- Designing Data Flow Diagram to relate the data entities and business functions that will be accommodated applications.

- Designing Class diagram that contains objects that support business functions identified

\subsubsection{Architecture Technology}

In designing architecture technology steps that must be done include :

- Identify technologies that can support data architecture and application architecture which has been designed so that the use of appropriate technology will be possible;

- Describing the concept of technology is built into a conceptual-frame.

\subsection{Methods of Implementation Plan Planning and Budget}

Implementation plan is a plan for the realization of the system to be built consists of the selection of programming languages, system test planning, preparation of human resources and other needs that will be required in the field. This implementation plan is useful in the implementation guide data architecture and architectural applications made for formulated into an information system that can be used in accordance with the initial requirements

\subsection{Implementation of the System}

In implementing the system, the authors made the development of information systems in accordance with the priorities that have been planned before the priority is based on the system which is the holding data from the planning system itself and proceed with system priorities that are identified using matrix data flow entity relationship data against business functions.

\subsection{Results Testing Method of Enterprise Architecture}

Testing of Enterprise Architecture is intended to test the draft that has been created is already in line with user needs, the needs of companies and the rules that apply in the planning process. In this test done with black-box and white box testing to users. Black-box testing intended to test whether the system has been designed according to the EA can be accepted by the user by using UAT (User Acceptance Testing), in addition to testing with UAT, authors also take functional tests performed by the user, in this case is part of planning and information system at Semarang State University using 
functional testing, the writer can see if the system is running properly according to its function.

\subsection{Analysis System Implemented}

Analysis of integrated planning information system which has been applied to an object of research conducted to obtain valid data on the implementation of the information system itself or not. Valid data that you want to search from the analysis of implementing information systems integrated planning is in the form of data changes between planning data and data realization.

\section{Results}

\subsection{Initialization and Identification Business Functions}

Initiation by the author in the planning system takes some of the information system that supports the objectives of the budget or the planning itself, the purpose of planning and budget is categorized into a number of things which the authors make it as an Key performance Indicator. The following indicators of success outlined by the initiation of the identification of the rules and the important things that become the primary function of the planning itself, it is:

- Integrated planning information systems can be used in the planning process and strategic plan of a unit / substructured organization (Budget support planning function).

- Integrated Planning Information System can be used for coordination (Budget support coordination function).

- Terintegras Planning Information System can be used in communicating in the budgeting process (Budget support communication functions).

- Integrated Planning Information System to motivate the executive in carrying out the activities that have been budgeted and can achieve the goals (Budget As a function of motivation).

- Integrated Planning Information System can be used as a means of controlling the activities (Budget as a Control and Evaluation).

- Integrated Planning Information System can be used as a means of optimizing activities to achieve the objectives of the strategic plan of the unit.

- Planning Information System can be used as a tool for monitoring the activities, so that the activities carried out does not deviate from the plan and strategy and organizational units (Budget as Education).

Information system who identified by the author and required in enterprise architecture planning information system including:

- Budgeting Information System

Budgeting information system is the primary system, which includes the main function of planning is to determination of possible activities and how to carry out these activities.

\section{- Systems Implementation Plan}

This information system is used to clarify the budget that were previously defined in the budgeting information system, and the benefits of this system is to explain as clearly as possible the steps of each activity to defining the detailed step-activity (time, person, place, spending details) by defining the full implementation of the realization is also easier because there is a guide implementation of the plan.

- Operational-Reporting System

This reporting information system is a system used to make a proposal before the project is implemented and used too for reporting activities that have been realized with details of activities undertaken.

\section{- LAKIP Information Systems}

This system is used as a support in the planning system because the system is required to support the reporting function in the budget.

Of the few systems that are described by the authors above have their respective different destinations that exist in these systems support the value chain so as to form a complete integrated system planning. The value chain that will result from the integration of the system described in Fig. 7.

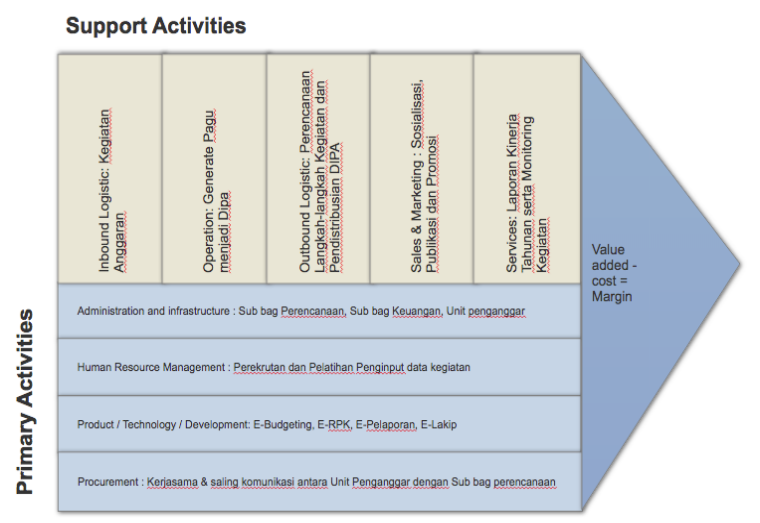

Fig. 7. Value Chain Planning System

\subsection{Data Architecture}

Based on the data entity identification by author on integrated planning information system generates the data entity relationships as shown in Fig. 8. 


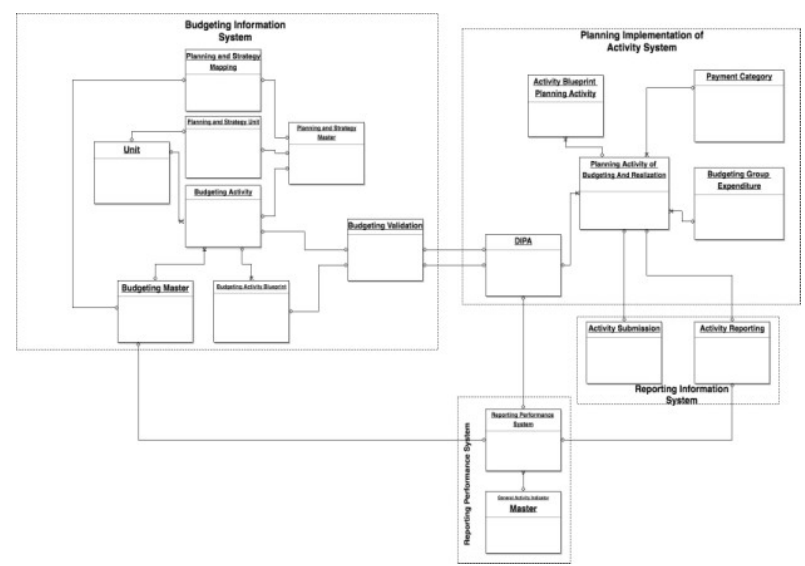

Fig. 8. Entity Relationship Data

\subsection{Application Architecture}

Products of this application architecture is use case, DFD, and also class diagram

\subsubsection{Use case Diagram}

In the integrated system described use case each actor to function. The planning information system is divided into 4 use case diagrams based on the function they have, the first diagram is used for the budgeting system in which the system is used to plan all budgeting within the university, this budgeting use case is shown on Fig. 9. Second is the use case used as the implementation plan of the activity, this use case explains and describes how the implementation of activities in the budgeting system will be implemented, this use case is shown on Fig. 10. Third is the use case used for reporting, this use case has a function to view the report between the budgeting system and its realization, the use case is shown on Fig. 11. The last use case used to see the performance of a unit seen from the achievement of the realized realization, the use case is shown on Fig. 12.

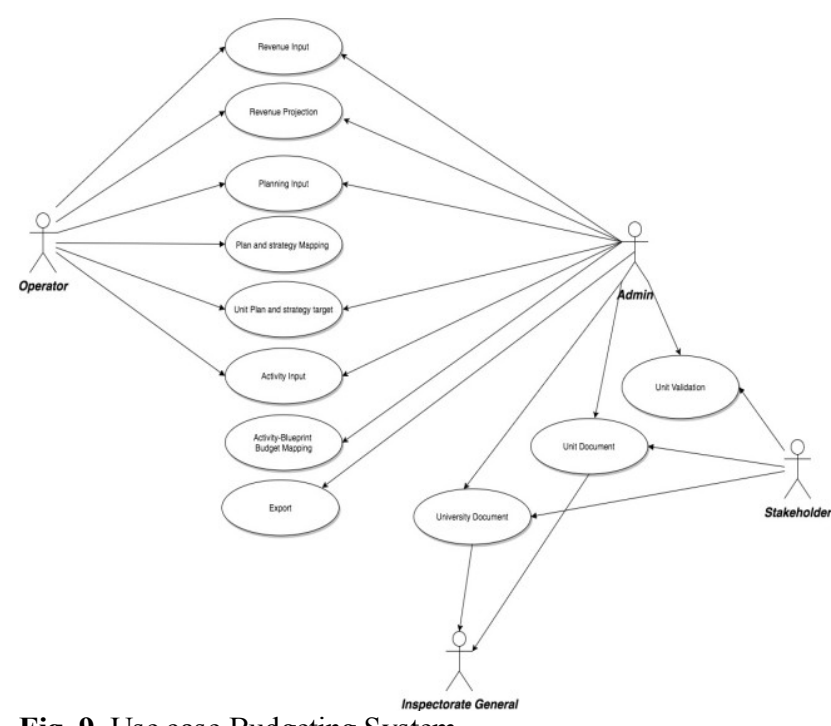

Fig. 9. Use case Budgeting System

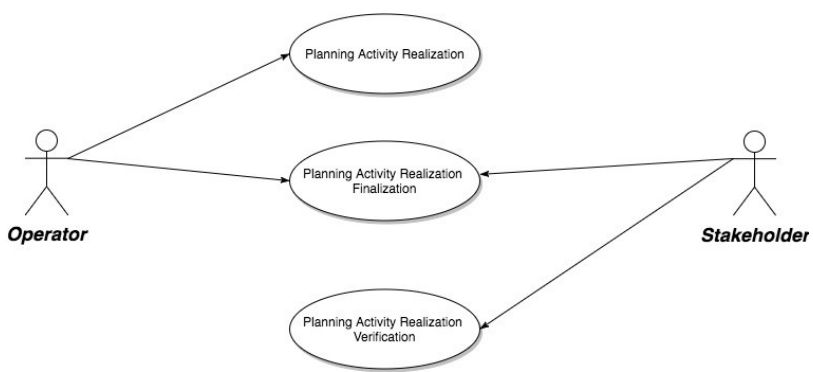

Fig. 10. Use case Planning Implementation of Activity System

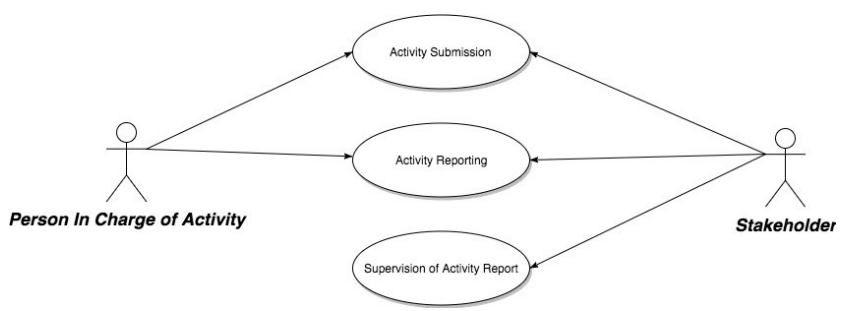

Fig. 11. Use case Activity Reporting System

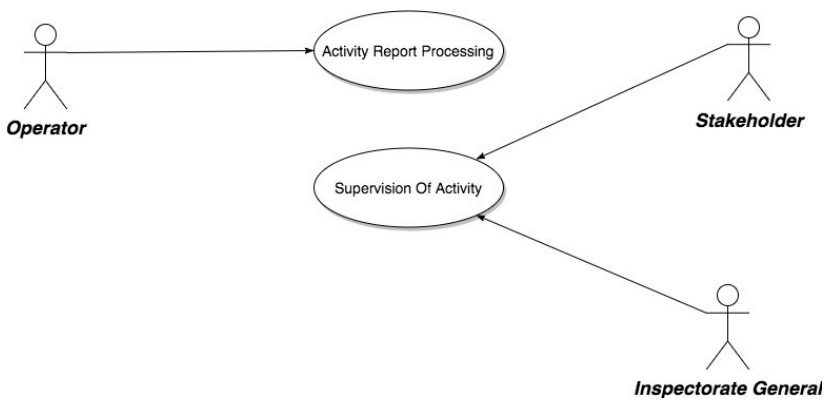

Fig. 12. Use case Reporting Performance System

\subsubsection{Class Diagram Planning system}

In facilitating the implementation of the system required class diagram that shows the relationship, dependency and the relationship between objects and classes that are contained in information systems planning. Class diagrams contained in the information system planning showed in Fig. 13.

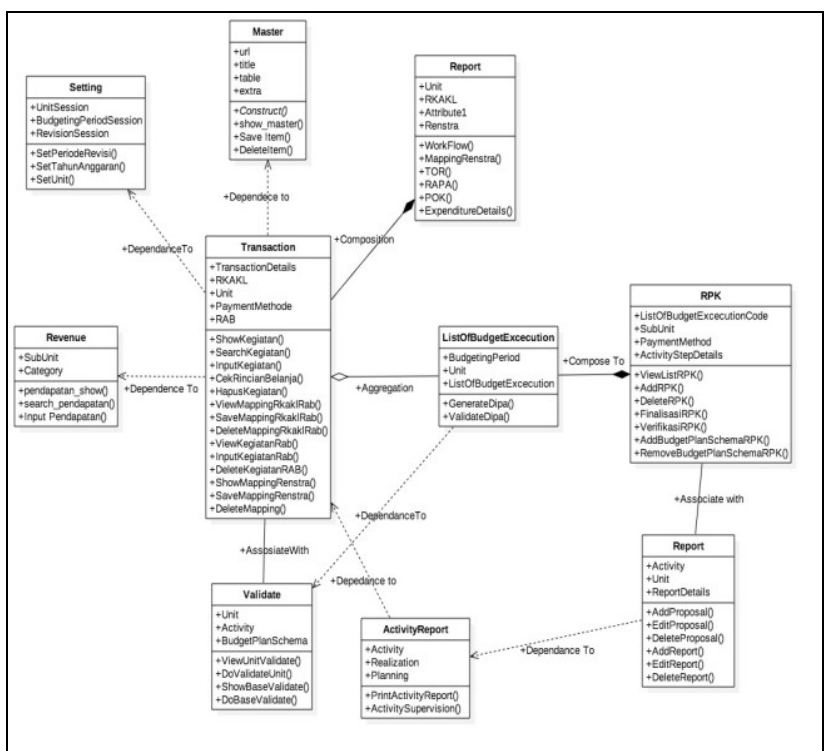

Fig. 13. Class Diagram Planning System 


\subsubsection{Architecture Technology}

In designing this architecture technology the author describes into the conceptual network architecture shown in Fig. 14.

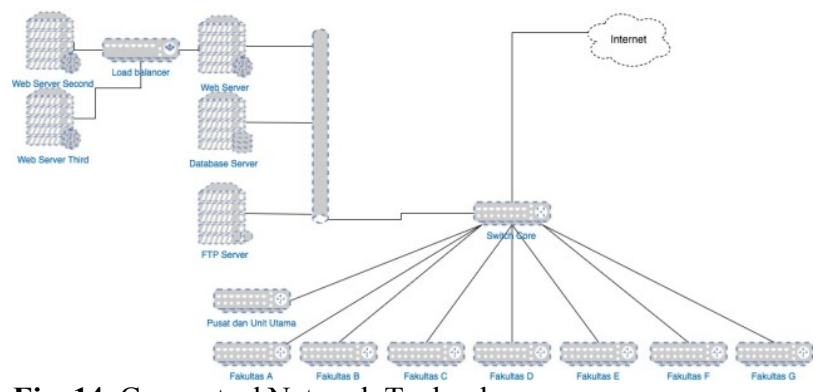

Fig. 14. Conceptual Network Technology

\subsection{Implementation of Application}

In the implementation, authors write the program code and create a database of architectural structure that has been designed. Then in the execution priorities author adjust to the importance of using entity relationship matrix data from flow data against business functions illustrated in Fig. 15, Due to the EAP approach has the principle application is made or form (create) done first than to other applications, so that the budgeting system has a priority to work earlier than other applications.

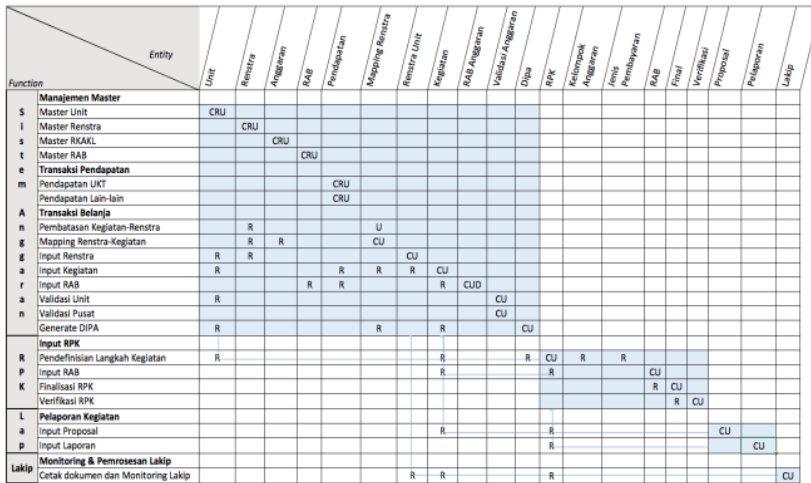

Fig. 15. Matrix Data Flow from Data Entity Relation to the Business function

\subsection{Testing Applications}

In testing this application the author use gray-box testing techniques, it is the merger between black box and white box testing techniques.

\subsubsection{Black box Testing}

Black box testing conducted by the author using two methods it is by User Acceptance Testing (UAT) and also functional test where the two tests are without looking at the structure of the programming code. UAT testing is done by using the instrument of acceptance taken from the success indicator that has been set and adjusted with the planning function. Here are the results of the UAT:

a. From the calculation results of questionnaires obtained from 45 respondents, the percentage of the value obtained from the ease and effectiveness of integrated planning information system that has been built has a percentage value of 168/45/5 x 100 $=75 \%$.

b. system planning information can be used in the process of planning plans and strategies of a unit / sub-organizations are structured so that all the planned activities of a unit within the budget in accordance with the plans and strategies that are owned by a unit so this application supports the planning function has a percentage value of $186 /$ $45 / 5 \times 100=83 \%$.

c. Information Systems integrated planning can be used to coordinate the budget so that every unit that exist within an organization can coordinate well and does not cause a miss conception between unit and providers of funds so that the planning system supports support functions of coordination has the percentage of the $166 / 45 / 5 \times 100=75 \%$.

d. Integrated Planning Information System can be used to communicate in the budgeting process so that everyone in the organization is responsible for the budget has been drawn up so that the system supports the planning information communication function has the percentage of $175 / 45 / 5 \times 100=$ $78 \%$.

e. Analysis of integrated information systems planning can motivate implementers in activities already budgeted and can achieve the goals that support the functions of information systems planning motivation has a percentage of $183 / 45 / 5 \mathrm{x}$ $100=81 \%$.

f. Analysis of information systems integrated planning can be used as a means of controlling the activities because the approved budget is the commitment of the implementers who participate in the preparation of the budget so that the system supports the function of controlling and evaluation has the percentage of the $182 / 45 / 5 \times 100=81 \%$,

g. Analysis of integrated planning information system can be used as a means of optimizing activities to achieve the objectives of the strategic plan unit has a percentage value of $185 / 45 / 5 \times 100=82 \%$.

h. Analysis of planning information systems can be used as a tool for monitoring the activities, so that the activities carried out does not deviate from the plan and strategy and organizational units so that the information system supporting the planning of educational functions has the percentage of the $161 / 45 / 5 \times 100=72 \%$.

As for the functional testing conducted by researchers from each of the test items in the form of business functions identified indicates success.

\subsubsection{Whit box Testing}

In the white-box testing these researchers used unit testing. Unit testing is code-based testing performed by the developer, this test is performed on each test individual units separately. White box testing results can be seen in Fig. 16. 


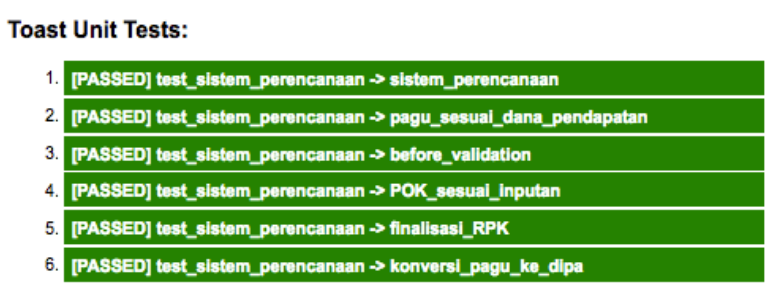

All tests completed in 5.1300 seconds

Fig. 16. White box Testing Results

\subsection{Information Systems Analysis}

The analysis was performed to determine that the system can control the activities of planning information to remain focused on the process of planning and implementation (realization), it is this which makes one of the added value (added value) of the integrated planning information systems that are built using EAP.

Analysis was performed using the planning and realization of the data prior to use integrated planning and information systems after usage of integrated information systems. Testing is done by finding the difference between the plan and the date of realization. If the difference is very high, it is indicates that the implementation or realization is not consistent and can be said to be planning to do less than the maximum. In the analysis of this system the authors saw that the time data from the planning and the time realized tends to retreat in its implementation. Writer screening data and finding the difference between the time data planning and implementation period. Data were analyzed by researchers tabulated on Table 1. The table shows that the average difference between before and after the use of information systems planning tends to fall.

Table 1. The average data tabulation Difference Planning and Realization

\begin{tabular}{|c|c|c|c|}
\hline$\overline{\text { Difference }}$ & Month & Year & Information \\
\hline $15: 48$ & January & 2016 & \multirow{11}{*}{$\begin{array}{l}\text { Before Use } \\
\text { Information } \\
\text { Systems }\end{array}$} \\
\hline $15: 34$ & February & 2016 & \\
\hline 15:11 & March & 2016 & \\
\hline 14.72 & April & 2016 & \\
\hline $15: 40$ & May & 2016 & \\
\hline $15: 33$ & June & 2016 & \\
\hline $15: 56$ & July & 2016 & \\
\hline $15: 26$ & August & 2016 & \\
\hline 15:14 & September & 2016 & \\
\hline 15.71 & October & 2016 & \\
\hline $15: 58$ & November & 2016 & \\
\hline 0:00 & December & 2016 & $\begin{array}{c}\text { Transition Year } \\
\text { Budget }\end{array}$ \\
\hline 1.80 & January & 2017 & \multirow{4}{*}{$\begin{array}{l}\text { After Usage } \\
\text { Information } \\
\text { System }\end{array}$} \\
\hline 1.80 & February & 2017 & \\
\hline 1.78 & March & 2017 & \\
\hline 1.75 & April & 2017 & \\
\hline
\end{tabular}

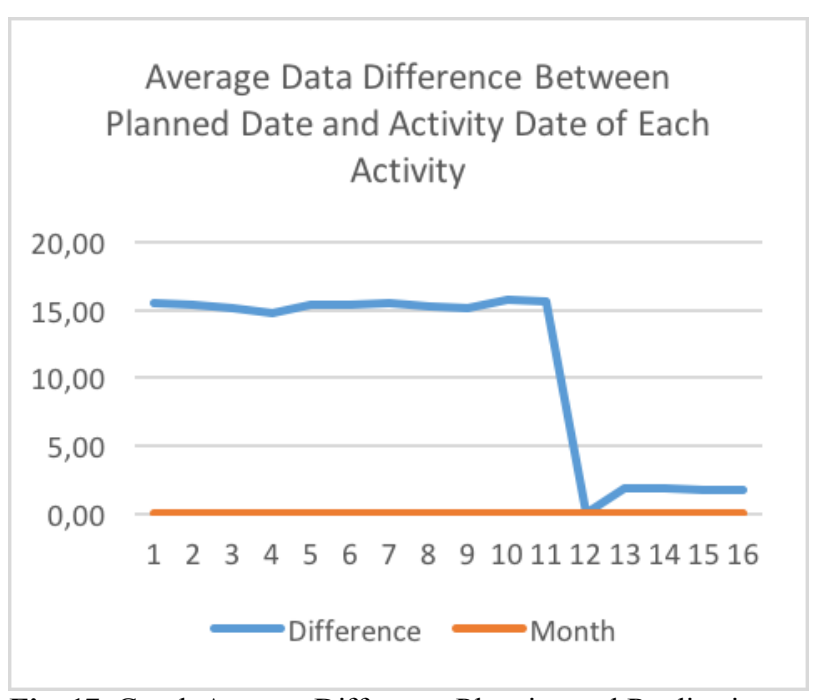

Fig. 17. Graph Average Difference Planning and Realization

\section{Conclusions}

Judging from the analysis of the User acceptance Test each question in User Acceptance Test has a percentage score above $70 \%$. This shows that the integrated information system that is designed to use EAP is effective and easy to use and most importantly information system integrated planning is in accordance with the functions of planning / budgeting is the planning, the coordination function, the communication function, the function of motivation, controlling and evaluation function and educational function.

Integrated planning information system has been able to motivate the executor in carrying out the activities that already budgeted, can be seen in the graph the average difference between execution of the activities carried out by the time budgeted in the plan, after implementation information system planning applied the difference between planning and realization is becoming less. This shows absorption of the budgeting information system makes budget more realized timely..

From the analysis of users acceptance Testing, planning system integrated is already qualified as a system of communication and coordination system between planner unit and provider of funds, as well as the result of the difference between the schedule of implementation and budgeting more timely because of the planning information system is definitely a miss conception between planner unit and provider of funds.

\section{References}

1. 1 J.K. Shim, J.G. Siegel, Budgeting Basics and Beyon. (2005)

2. 2 B. Kurniawan, Enterprise Architecture Planning Sistem Informasi Pada Perguruan Tinggi Swasta Dengan Zachman Framework, 1, 21 (2011)

3. 3 B. Bellman, R. Felix, Enterprise Architecture for e-Government 1, 48 (2004)

4. 4 S. Bente, B. Uwe, L. Shailendra, Collaborative Enterprise Architecture (2012) 
5. 5 S. Spewak, M. Tiemann, Updating The Enterprise architecture planning model,11 (2006)

6. 6 B. Dantu, S. Eric, Budgeting Basics and Beyond, 6, 76 (2005)

7. 7 S. Spewak, Enterprise Architecture Planning (Developing a Blueprint for Data, Application and Technology). (1992)

8. 8 M.E. Porter, Competitive Advantage : Creating and Sustaining Superior Performance : with a new introduction. (1985)
9. 9 M.E. Khan, F. Khan. International Journal of Advanced Computer Science and Applications, 6, 12 (2012)

10. 10 R. Black, Managing the Testing Process : Practical Tools and Techniques for Managing Hardware and Software Testing 3,(2009)

11. 11 M. Nafarin, Penganggaran Perusahaan, (2007)

12. 12 M. Munandar. Budgeting: Perencanaan Kerja, Pengkoordinasian Kerja, Pengawasan Kerja. Cetakan Ketigabelas (2000) 